\title{
AD1289以来北极巴伦支海-喀拉海秋季海冰 范围的重建
}

\author{
张琦 ${ }^{1}$, 效存德 $^{2 *}$, 丁明虎 ${ }^{1}$, 窦挺峰 $^{3}$ \\ 1. 中国气象科学研究院极地气象研究室, 北京 100081 ; \\ 2. 北京师范大学地表过程与资源生态国家重点实验室, 北京 100875 ; \\ 3. 中国科学院大学资源与环境学院, 北京 100049 \\ * 通讯作者, E-mail: cdxiao@bnu.edu.cn
}

收稿日期：2017-11-12; 收修改稿日期：2018-01-25; 接受日期：2018-03-26; 网络版发表日期：2018-04-25 国家自然科学基金杰出青年科学基金项目(批准号：41425003)、中国科学院先导性专项项目(编号：XDA19070103)、中国气象科学研究院极 地大气科学野外观测基地和中国科学院冰冻圈科学国家重点实验室开放基金项目(编号: SKLCS-OP-2016-03)资助

摘要篎选了北极地区巴伦支海-喀拉海(B-K海)周边陆地及岛屿上的冰芯和树轮资料, 保留对该海域海冰范围 (SIE)指代意义强的代用资料，分别采用普通最小二乘回归法(权重综合序列回归和普通多元回归)、主成分回归 法和偏最小二乘回归法重建了B-K海1289 1993年秋季SIE序列, 并与近几十年观测结果进行检验和续接. 通过模 型的统计参数对不同方法的结果进行评估和对比, 剔除偏差较大的普通多元回归法, 对其余方法的结果用解释方 差做权重合成，最终得到一条稳健性更高的序列. 结果表明：13世纪末期到18世纪末期，B-K海秋季SIE处于高位 振荡的状态，且整体有小幅上升趋势，反映了小冰期(LIA)气候背景下该海域SIE显著的多年代际变化特征。从18 世纪末期开始, 该海域SIE开始减小, 在19世纪中后期减小趋势非常显著, 并一直持续到20世纪30 40年代, 该阶段 是B-K海SIE的相对低值期. 20世纪40 70年代, 该海域SIE有所回升, 但在 20 世纪70年代后又进入一个快速退缩期, 并一直持续至今. 18 世纪后期以来, B-K海SIE退缩程度无论在持续时间还是速率上, 都是过去700多年来前所未有 的, 这很有可能与工业革命以来人类活动的影响有关. 20 世纪 70 年代之后是SIE退缩最显著的时期, 其减小速率是 之前平均的6.18倍, 20 世纪70年代后北极SIE很可能是近千年来的最低值.

关键词北极海冰, 冰芯, 树轮, 古气候重建, 全球变暖

\section{1 引言}

在全球变暖的背景下，近30年来北极地区增温幅 度约为全球平均值的两倍多(Cohen等, 2014), 北极海 冰范围也迅速减小，其大范围退缩既是对北极迅速增
暖的响应，又是进一步促进北极迅速增暖的驱动力, 是北极“放大器”效应的重要机制之一(Screen 和Simmonds, 2010; Walsh, 2014; Liu等, 2016). 近些年来, 欧 亚大陆和美洲大陆中纬度地区冬季极端寒潮事件频 发, 一些学者研究认为这与北极迅速增温以及北极海 
冰迅速减少密切相关. 北极海冰偏少的年份极浴易偏 弱，急流经向性增强，北极的冷空气更易大规模南下 到中纬地区, 给当地带来极端寒潮天气(Francis等, 2009；Honda等，2009；Liu等，2012；Tang等，2013; Overland等, 2015). 巴伦支海-喀拉海(B-K海)被认为是 欧亚大陆寒潮的发源地之一, 是影响欧亚大陆冬季冷 空气活动的关键海区. 研究表明，秋、冬季该海域海 冰异常偏少时，当年冬季欧亚大陆更易发生极端寒潮 事件(武炳义等，2004；Petoukhov和Semenov，2010; Wu等, 2011; Hopsch等, 2012; Inoue等, 2012). 包括中 国在内的东亚地区是受极端天气气候事件频繁侵扰的 地区，近年来冬季发生了罕见强寒潮事件，例如中国 2008年的南方冰冻雨雪灾害及2016年的“霸王级”寒 潮. 因此, $\mathrm{Wu}$ 等(2011)、武炳义和杨琨(2016)提出可把 北极 B-K海前期的海冰(如9月平均的海冰密集度)作为 中国冬季气温的一个预测因子. 但是, 也有一些学者认 为近些年北半球中纬度地区频发的极端冷事件是大气 内部变率的作用，与北极海冰的变化并无显著联系 (Barnes，2013; Barnes和Screen, 2015; McCusker等, 2016). 争议存在的主要原因之一是北极海冰卫星观测 资料时间长度有限(不足 40 年), 无法在长时间尺度上 分析北极海冰的变化及其成因. 而如海冰图表、航海 记录和捕鲸等能间接反映SIE的资料存在时空分布不 均匀, 不确定性大等缺陷, 严重制约了我们对于北极海 冰自然变率的认识, 为研究北极海冰变化与中纬度地 区冬季极端天气气候事件之间的关联带来了较大的困 难. 因此, 恢复高信度的历史时期北极SIE序列, 在更长 时间尺度上分析其变化特征十分必要.

目前恢复历史时期海冰序列的方法主要有气候代 用资料重建和气候模式模拟两种(Jones和Mann, 2004). 现阶段气候模式结果的精确度还较为有限(Goosse等, 2006; Muscheler等, 2007), 而代用资料重建法可以通过 篮选指代意义强的高分辨率代用资料提高结果的可靠 性(Jones, 2016; PAGES 2k Consortium, 2013), 本文采 用代用资料重建法来恢复历史时期的北极SIE. Xiao等 (2015)在重建过去300年南印度洋SIE时指出，用古气 候代用资料重建SIE时只能重建其最大或最小范围, 而难以重建其平均状态. 目前对于北极海冰的重建大 多也是针对海冰的最大或最小范围展开的. Fauria等 (2010)利用斯瓦尔巴德地区的冰芯 $\delta^{18} \mathrm{O}$ 和斯堪的纳维 亚地区的树轮宽度作为代用资料，重建了北欧海区
AD1200以来的海冰最大范围. Shapiro等(2003)整理了 挪威的海冰表和苏联的飞机侦查图, 重建了 AD1850 2001年巴伦支海4月SIE．Kinnard等(2011)利 用环北极地区的代用资料集(冰芯、树轮、湖泊沉积 物等)重建了过去1450年来的夏末(8月)北极SIE. 考虑 到代用资料(尤其树木在夏秋为生长季)的指代意义, 以及 9 月份该海域近些年可能出现的无冰状况, 本文将 重建北极关键海区一—巴伦支海-喀拉海海区9月前后 (8 10月，用以代表海冰年最小范围，并将该时段定义 为秋季)的SIE. 通过对该海域周边的代用资料进行质 量控制和笁选，最终重建了1289 1993年喀拉海-巴伦 支海秋季SIE序列，并对过去百年尺度该区域的海冰 变化特征及原因做初步探讨.

\section{2 数据与方法}

\section{1 海冰观测数据}

本文用于比对气候代用资料的海冰观测资料来自 NASA GSFC(NASA's Goddard Space Flight Center)提 供的1978年11月至2012年12月北极海冰范围卫星观测 资料(https://neptune.gsfc.nasa.gov/csb/index.php?secti\% $20 \mathrm{on} \% 20=59)$, 以及美国国家冰雪数据中心(NSIDC, National Snow and Ice Data Center)提供的1933 2006 年俄罗斯北极沿海地区的海冰资料(http://nsidc.org/ $\mathrm{data} / \mathrm{G} 02182)$. 两套资料均为月分辨率资料，由于海区 划定及计量标准存在一些差别, 两者在数值上略有差 异，但变化趋势基本一致(图 $1 \mathrm{~b}$ ), 在重叠时段 (1979 2006)相关系数高达 $0.81(p<0.01)$. 为得到更长的 海冰观测序列用于重建, 本文采用最小二乘法将 NSIDC海冰资料与卫星资料进行融合, 最终得到了 1956 2012年B-K海8 10月的SIE序列(图1a).

\section{2 古气候代用资料类型及指代意义}

本文用于重建海冰范围的代用资料来源于目标海 区周边的冰芯和树轮资料. 在资料篮选过程中分 3 步进 行质量控制. 首先, 根据地理位置篮选出分布于B-K海 区周边(纬度范围: $0^{\circ} \sim 110^{\circ} \mathrm{E} ， 60^{\circ} \mathrm{N}$ 以北)的代用资料. 然后对初篮完的代用资料与海冰观测资料进行相关分 析, 保留显著性高 $(p<0.1)$ 的资料. 最后在前人的研究基 础上，根据相关分析的结果剔除指代意义不明确的代 用资料. 最终得到用于重建B-K海SIE的代用资料集 

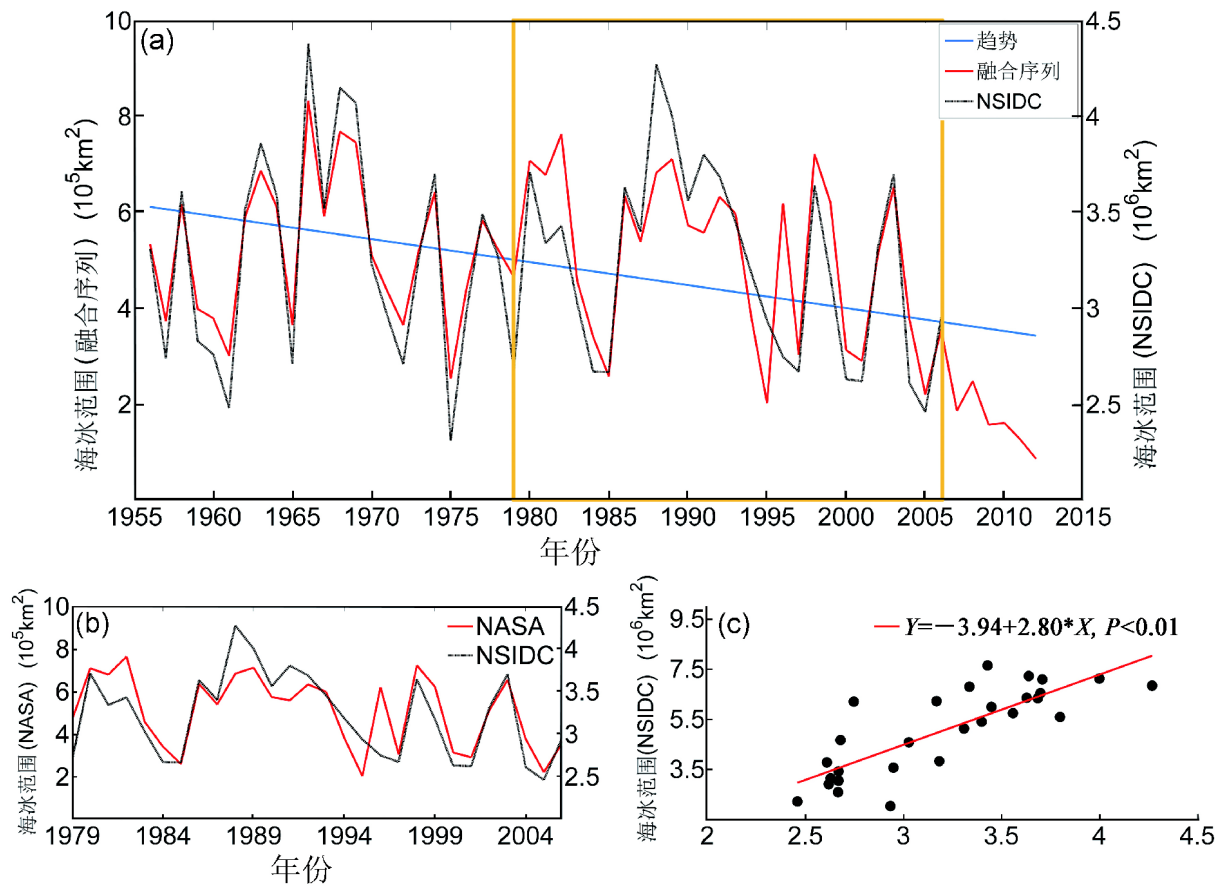

图 1 NASA和NSIDC海冰资料B-K海SIE对比和融合

(a) 海冰融合序列(1956 2012), 黄框表示序列融合的基准时段; (b) 两序列在重叠时段(1979 2006)的对比; (c) 两序列的散点图及拟合结果 $(X$ 和 $Y$ 轴分别表示NSIDC和NASA海冰资料)

(空间分布如图2所示, 详细信息见表1).

海冰的空间分布范围跨度大，其变化受到大气和 海洋中多种要素共同影响. 选取多种代用资料进行融 合重建, 可以提高结果的可靠性(Abram等, 2013; Kinnard等，2011). 本文所选的古气候代用指标包括冰芯 中的 $\delta^{18} \mathrm{O} 、 \mathrm{Na}^{+} 、 \mathrm{MSA}$ 和树轮轮宽. 冰芯中的 $\delta^{18} \mathrm{O}$ 可以 作为气温的指示器, 反应历史时期降雪在冰川(盖)上 积累时的温度。北极地区大部分降雪集中在秋季 (Screen和Simmonds, 2012), 因此 $\delta^{18} \mathrm{O}$ 对北极地区秋季 的温度更具指示意义. 基于温度与SIE的负相关关系, 因此可用 $\delta^{18} \mathrm{O}$ 来间接反映历史时期SIE的变化．在极 区，温度是树木生长的主要限制因子，树轮轮宽可以 在一定程度上反映树木生长季的温度变化. 因此, $\delta^{18} \mathrm{O}$ 和轮宽均可作为温度的代用指标，间接反应SIE的变 化，同时它们与SIE之间应为负相关关系. 可以认定不 满足此条件的资料指代意义不明确，在资料筛选过程 中予以剔除.

对于SIE的重建, 除了有温度代用资料作为对气候 背景的反映之外, 也需加入海源物质代用指标, 作为对
SIE的直接反映. 海洋中的飞沫在大气中破碎会使海盐 离子 $\left(\mathrm{Na}^{+} 、 \mathrm{Cl}^{-}\right.$等 $)$进入大气, 这些海盐离子一部分在开 阔海域沉降, 一部分则随着大气环流输送到周边陆地 冰川(盖)上沉降(Lewis和Schwartz，2004; Yang等, 2008). 假定大气环流的强度和路径一样, 且开阔海域 是海盐离子的主要来源, 若SIE越大(小), 则开阔海域 到冰盖间的距离越远(近), 随大气输送的途中离子沉 降越多(少), 冰盖上最终沉降的海盐离子含量越少 (多), 即SIE与冰芯中的海盐离子含量负相关(Benassai 等, 2005; Kekonen等, 2005; Röthlisberger等, 2010). 但 由于大气的脱氯作用(Röthlisberger等, 2003), $\mathrm{Na}^{+}$较 $\mathrm{Cl}^{-}$可更好的反应海盐离子的含量, 所以本文只采用 $\mathrm{Na}^{+}$来进行重建. MSA(甲基磺酸)是海冰边缘海洋生物 活动生成的DMS(二甲基硫)氧化而成的, 经过大气环 流输送到冰川(盖)上沉降. 类似于海盐离子, MSA也可 以在一定程度上指示SIE的变化(Curran等, 2003; Xiao 等, 2015). 本文最终选择 $\mathrm{Na}^{+}$和MSA作为海源代用资料 与温度代用资料 $\left(\delta^{18} \mathrm{O}\right.$ 和轮宽 $)$ 融合，进行目标海区SIE 的重建. 


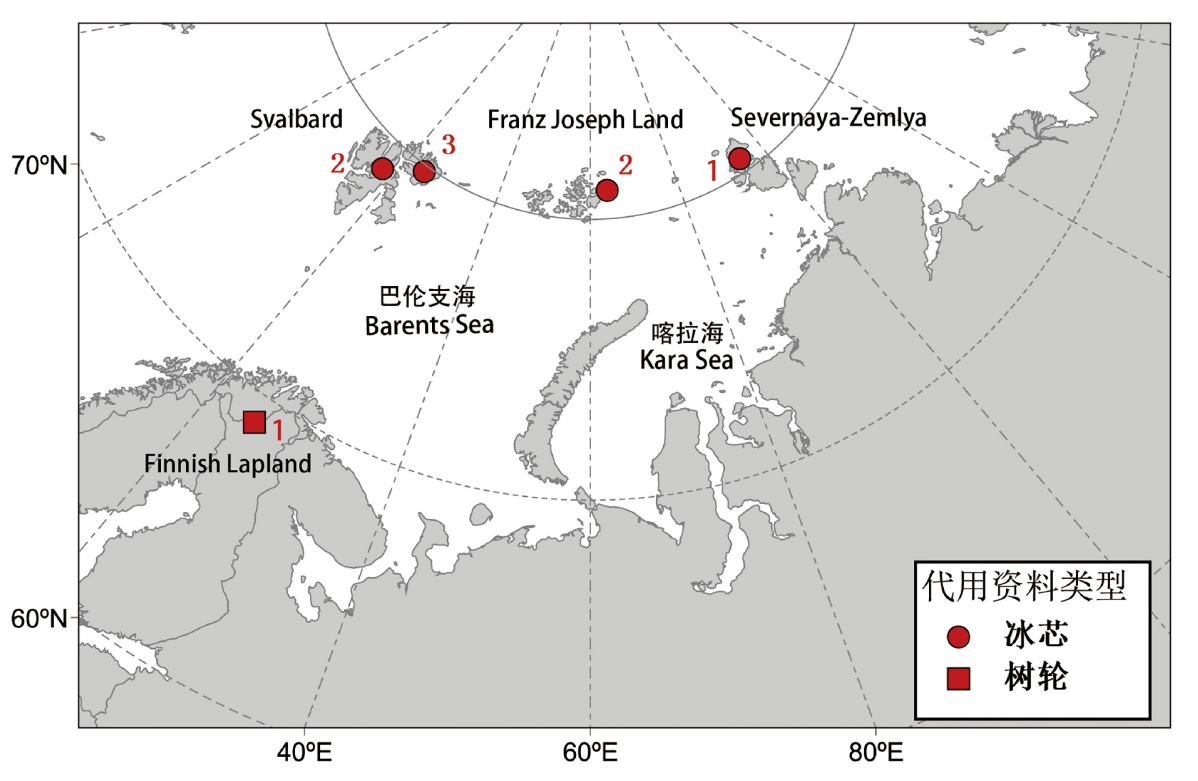

图 2 代用资料类型及空间分布图

点旁边的数字表示该点代用指标数量

表 1 代用资料的详细信息 ${ }^{a)}$

\begin{tabular}{|c|c|c|c|c|c|c|c|}
\hline 标号 & 类型 & 地点 & 纬度 & 经度 & 起止年 & 相关系数 & 来源 \\
\hline P1 & 冰芯 $\delta^{18} \mathrm{O}$ & SA & $79.8^{\circ} \mathrm{N}$ & $24^{\circ} \mathrm{E}$ & $1400 \sim 1998$ & $-0.49 * *$ & $\begin{array}{l}\text { Isaksson等, } \\
\text { 2005a }\end{array}$ \\
\hline P2 & 冰芯 MSA & SL & $78.9^{\circ} \mathrm{N}$ & $17.4^{\circ} \mathrm{E}$ & $1121 \sim 1996$ & $-0.32 *$ & $\begin{array}{l}\text { Isaksson等, } \\
2005 b\end{array}$ \\
\hline P3 & 冰芯 $\mathrm{Na}^{+}$ & SL & $78.9^{\circ} \mathrm{N}$ & $17.4^{\circ} \mathrm{E}$ & $1121 \sim 1996$ & $-0.31 *$ & $\begin{array}{l}\text { Kekonen等, } \\
2005\end{array}$ \\
\hline P4 & 冰芯 $\mathrm{Na}^{+}$ & $\mathrm{SZ}$ & $80.5^{\circ} \mathrm{N}$ & $94.8^{\circ} \mathrm{E}$ & $900 \sim 1998$ & $-0.33 * *$ & Opel等, 2013 \\
\hline P5 & 冰芯 $\delta^{18} \mathrm{O}$ & SA & $79.8^{\circ} \mathrm{N}$ & $24^{\circ} \mathrm{E}$ & $1280 \sim 1998$ & $-0.46^{* *}$ & $\begin{array}{c}\text { Isaksson等, } \\
2005 \mathrm{c}\end{array}$ \\
\hline P6 & 冰芯 $\delta^{18} \mathrm{O}$ & FJL & $81^{\circ} \mathrm{N}$ & $64^{\circ} \mathrm{E}$ & $1225 \sim 1996$ & $-0.50 * *$ & $\begin{array}{l}\text { Henderson, } \\
2002 .\end{array}$ \\
\hline $\mathrm{P} 7$ & 树轮轮宽 & FL & $69^{\circ} \mathrm{N}$ & $25^{\circ} \mathrm{E}$ & $0 \sim 2005$ & $-0.35^{* *}$ & Helama等, 2010 \\
\hline P8 & 冰芯 $\mathrm{Na}^{+}$ & SA & $79.8^{\circ} \mathrm{N}$ & $24^{\circ} \mathrm{E}$ & $1303 \sim 1998$ & $-0.30^{*}$ & $\begin{array}{c}\text { Motoyama等, } \\
2001\end{array}$ \\
\hline P9 & 冰芯 $\mathrm{Na}^{+}$ & FJL & $81^{\circ} \mathrm{N}$ & $64^{\circ} \mathrm{E}$ & $1227 \sim 1996$ & $-0.36^{* *}$ & Henderson, 2002 \\
\hline
\end{tabular}

a) **表示可以通过 0.05 显著性检验; *表示可以通过 0.1 显著性检验. 地点简写分别表示: SA, Svalbard Austfonna; SL, Svalbard Lomonosofonna; SZ, Severnaya-Zemlya; FJL, Franz Joseph Land; FL, Finnish Lapland. 起止年代用资料分辨率均为 1 年

\section{3 主要重建方法}

由于代用资料长度不一致，在重建中分为两个时 段(1402 1993和1289 1401)，代用资料和海冰观测资 料标定时段均为1956 1993. 在重建方法上, 本文采用 了普通最小二乘回归法, 主成分回归法(PCR)和偏最小
二乘回归法(PLSR). 根据对代用资料序列预处理方式 不同，普通最小二乘回归法又分为权重综合序列回归 法(SLR)和普通多元回归法(OR). SLR 是先将代用资料 用其与SIE之间的相关系数作为权重合成一条综合序 列后再进行计算, 而OR直接对代用资料集进行回归计 
算. 由于普通最小二乘回归法和主成分回归法较为常 见, 这里仅介绍偏最小二乘回归法(PLSR).

偏最小二乘法(PLSR) 是从自变量和因变量中分 别提取主成分, 并使得两者之间的相关性最高, 在一定 的误差允许范围内重复此步骤以提取主成分信息进而 建立回归模型. 这样建立的回归模型既可避免过拟合, 也可使得自变量对因变量有较好的解释性. Kinnard等 (2011) 认为无法确切知道陆源代用资料(冰芯、树轮 等)对SIE的指代意义是否显著, 用简单的回归方法重 建SIE可能效果不佳; 为避免代用资料指代意义不明 确的问题, 他在重建北极SIE的过程中没有分别讨论 各代用资料的指代意义, 而是直接采用PLSR法对代用 资料集进行重建计算, 最终得到了较为可信的结果. 为 了保证重建结果的可靠性, 本文也采用了PLSR法重建 SIE. 需要指出的是, 在采用普通最小二乘回归法(SLR 和 $\mathrm{OR})$ 和主成分回归法(PCR)重建时, 本文选用了显著 性更高 $(p<0.05)$ 的代用资料 $(\mathrm{P} 1 、 \mathrm{P} 4 、 \mathrm{P} 5 、 \mathrm{P} 6 、 \mathrm{P} 7$ 和 P9). 而基于偏最小二乘回归法的优势, 选用所有代用 资料 $(p<0.1)$ 来进行重建, 进一步通过不同的代用资料 来验证各方法结果的对应程度, 通过对比也可检验本 文的重建方案是否可靠.

PLSR 具体算法步骤如下:

(1) 从对 $\mathbf{X}, \mathbf{Y}$ 分别做 $\mathrm{EOF}$ 分解, 提取前 $a$ 个特征 向量:

$$
\begin{aligned}
& \mathbf{X}=\mathbf{T}_{1} \mathbf{P}_{1}^{\prime}+\mathbf{E}_{1}, \\
& \mathbf{Y}=\mathbf{T}_{1} \mathbf{Q}_{1}^{\prime}+\mathbf{F}_{1},
\end{aligned}
$$

式中, $\mathbf{T}_{n \times a}$ 是得分矩阵 (score), $\mathbf{P}_{m \times a}$ 和 $\mathbf{Q}_{m \times a}$ 是荷载矩阵 (loading), $\mathbf{E}_{1}$ 和 $\mathbf{F}_{1}$ 是残差矩阵.

式(2)重复式(1)中的步骤, 对残差矩阵 $\mathbf{E}_{1}$ 和 $\mathbf{F}_{1}$ 做 EOF分解:

$$
\begin{aligned}
& \mathbf{E}_{1}=\mathbf{T}_{2} \mathbf{P}_{2}^{\prime}+\mathbf{E}_{2}, \\
& \mathbf{F}_{1}=\mathbf{T}_{2} \mathbf{Q}_{2}{ }^{\prime}+\mathbf{F}_{2} .
\end{aligned}
$$

以此类推, 进行迭代运算. 最终可得

$$
\begin{gathered}
\mathbf{X}=\mathbf{T}_{1} \mathbf{P}_{1}^{\prime}+\mathbf{T}_{2} \mathbf{P}_{2}^{\prime}+\ldots+\mathbf{T}_{r} \mathbf{P}_{r}^{\prime}+\mathbf{E}_{r}, \\
\mathbf{Y}=\mathbf{T}_{1} \mathbf{Q}_{1}{ }^{\prime}+\mathbf{T}_{2} \mathbf{Q}_{2}{ }^{\prime}+\ldots+\mathbf{T}_{r} \mathbf{P}_{r}^{\prime}+\mathbf{F}_{r} .
\end{gathered}
$$

一般情况下, 偏最小二乘法并不需要选用存在的 $r$ 个成分 $\left(\mathbf{T}_{1}, \mathbf{T}_{2}, \ldots \mathbf{T}_{r}\right)$ 来建立方程, 选用前 $p$ 个成分 $(p \leqslant r)$ 即可得到预测能力较好的回归模型. 可以通过交叉有
效性检验来确定所需提取的主成分个数, 本文采用留 一交叉验证法.

\section{4 验证方法}

在建立回归模型后, 需要验证预测结果的稳定性, 以评估模型的泛化能力. 只有泛化能力高的模型, 才可 得到可靠的SIE重建序列. 对模型泛化能力的验证一般 有两种方法: 分段交叉验证法和留一交叉验证法 (leave-one-out). 本文的海冰观测序列长度较短, 留一 交叉验证法更为合适，具体步骤是：对所有资料每次 预留其中一个, 用于验证基于剩余资料建立的模型的 预测能力. 通过验证集得到的预测值及其实际值，可 计算误差缩减值(RE, Reduction of Error)来评估该模 型的泛化能力.

误差缩减值(RE): 这是精确检验气候重建稳定性 的统计量, 它具有有效的诊断能力, 是一个敏感的统 计量, 但也易受到个别极值的影响. 其计算公式为

$$
\mathrm{RE}=1-\left[\frac{\sum_{1}^{n}\left(x_{i}-\widehat{x}_{i}\right)^{2}}{\sum_{1}^{n}\left(x_{i}-\overline{x_{c}}\right)^{2}},\right.
$$

式中, $x_{i}$ 和 $\widehat{x}_{i}$ 是验证时段的实测和预测值, $\overline{x_{c}}$ 是校准时 段实测值的平均值. RE的取值范围是 $(-\infty, 1]$, 当RE为 正值是表明回归模型具有一定的可靠性, 越接近 1 则表 明重建结果越好. 当RE为负值时, 一般认为两个序列 没有相关性. 用留一交叉验证法进行检验时, 误差缩减 值(RE)和有效系数(CE, Coefficient of Efficiency)相等.

Durbin-Watson(D-W)系数: 可以用来检验回归模 型中的残差是否存在自相关现象, D-W 统计量的取值 范围是 $0 \sim 4$, 当残差一阶正相关时, D-W系数接近 0 ; 当 残差一阶负相关时, $\mathrm{D}-\mathrm{W}$ 系数接近 4 ; 当 $\mathrm{D}-\mathrm{W}$ 系数接近 2 时, 表明模型残差独立, 有一定可靠性.

\section{3 结果与讨论}

\section{1 各方法重建的结果}

\subsection{1 普通最小二乘回归法(SLR和OR)重建结果}

两种普通最小二乘回归法重建的B-K海秋季 SIE 在变化趋势上表现较为一致, 但变化幅度略有差异(图 3). 两种方法的结果均表明: 13世纪末至18世纪末B-K 海秋季SIE表现为显著的多年代际变化特征, 且处于一 

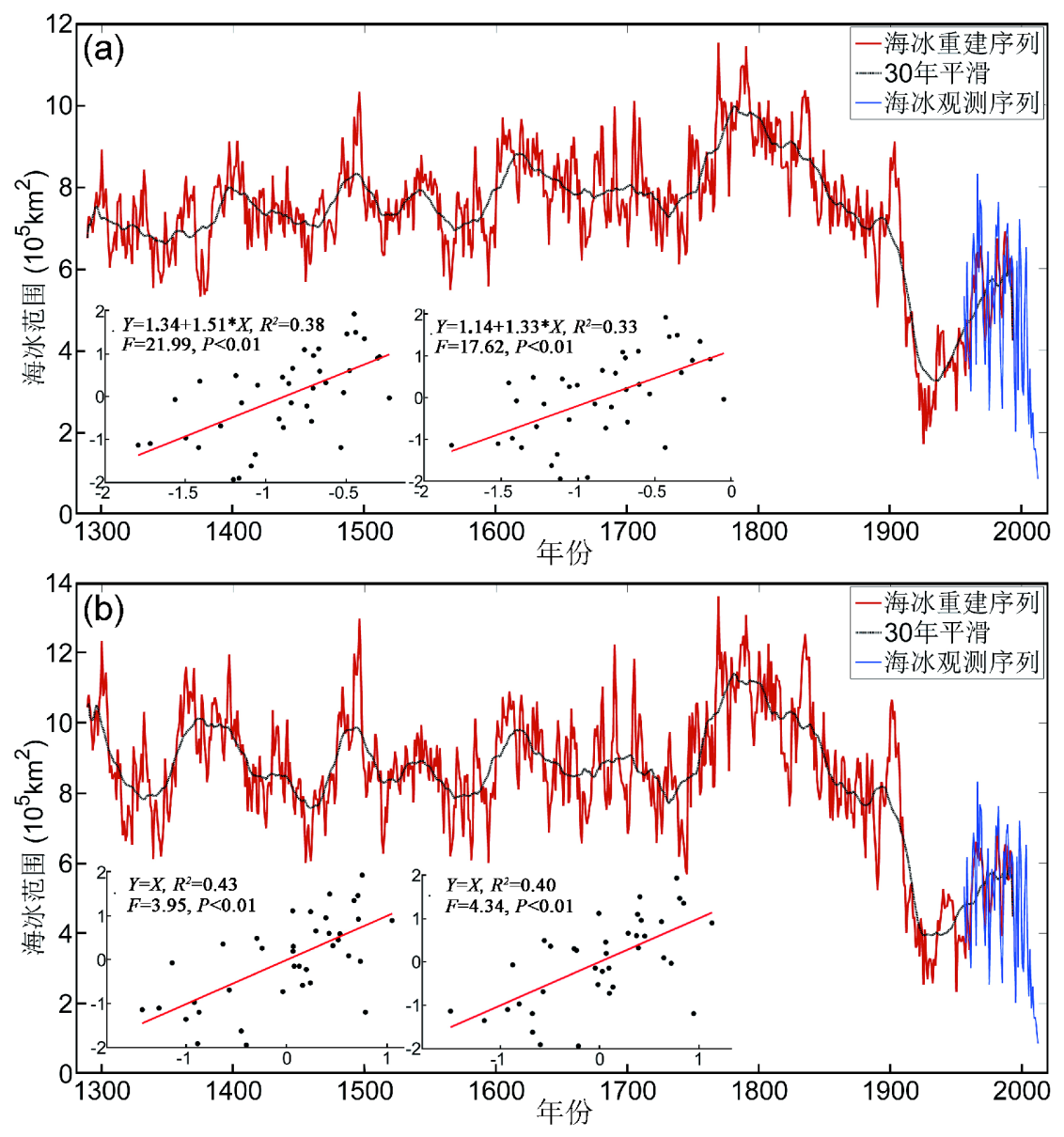

图 3 普通最小二乘回归法重建结果

(a) 权重综合序列回归法; (b) 普通多元回归法. 插图分别表示两段重建(1402 1993和1289 1401)的序列散点图及线性拟合结果 $(X$ 和 $Y$ 轴分别表 示代用资料和海冰资料, 下同)

个相对的高值阶段. 从18世纪末期开始，该海域SIE开 始持续的减小, 并在19世纪末期加速减小, 并一直持续 到20世纪30 40年代左右. 相对而言, 20 世纪30 40年 代是SIE的一个低值期. 20 世纪40 70年代SIE有所回 升，但20世纪70年代后又开始大幅度下降. 这两种方 法的结果虽有一定相似性，但它们表现的SIE变化幅 度存在差异. OR结果表现的13世纪末至18世纪末SIE 变化幅度更大, 序列的方差更大, 且数量级比SLR结果 大 $10^{5} \mathrm{~km}^{2}$. 并且, SLR结果表现出该时段内SIE有小幅 上升趋势, 而 $\mathrm{OR}$ 结果表现为均位振荡. 同时, 这两种方 法对 20世纪30 40年代SIE达到的低值范围表现有差 异, SLR重建的SIE在18世纪末以来的减小程度更大, 在20世纪30 40年代达到的低值更低.

进一步对两种方法的统计参数进行分析. SLR两
段重建的回归模型解释方差分别为 $0.36(1402 \sim 1993$ 年) 和 $0.32(1289 \sim 1401$ 年), OR为 $0.43 / 0.40 . F$ 检验值分别为 21.99/17.62(SLR)和3.95/4.34(OR). 可以看出, OR的解 释方差较高, 但 $F$ 值却远小于SLR. 且在第二段重建中, 代用资料减少, OR结果的 $F$ 值却升高了, 说明 OR方法 的重建结果可能存在过拟合. 进一步用舍一交叉验证 法计算RE: 0.31/0.26(SLR)和0.17/0.19(OR). 可以看出, SLR模型的泛化能力要明显优于OR模型. 代用资料减 少后(第二段重建), OR结果的RE值却变高了, 表明其 过度拟合了代用资料和海冰观测资料. 从表 2 也可看 出，部分代用资料之间相关性非常高，存在着严重的 多重共线性. 直接通过普通多元回归法(OR)建模易产 生过度拟合, 得到的回归模型泛化能力不佳. 而将代 用资料通过权重合成后再进行建模(SLR), 则可在一 
定程度上避免过拟合, 得到相对可靠的结果.

\subsection{2 主成分回归法(PCR)重建结果}

在上述重建过程中, 由于代用资料间的多重共线 性造成了OR方法的过度拟合, 虽然其结果有更高的解 释方差, 但是模型的RE值较小, 泛化能力较差. 本文进 一步采用主成分回归法(PCR)对普通多元回归法(OR) 进行改进, 与SLR模型结果进行对比. 主成分回归法 (PCR)可以去除代用资料间的咒余信息, 建立一组相 互独立的综合指标, 可改善OR模型的过拟合问题. 对 代用资料集相关系数矩阵进行EOF分解后, 在两段重 建中均提取前两个主成分(方差贡献量分别为 $83.1 \%$ 和 $82.2 \%$ )进行建模计算. PCR的重建结果(图4)与SLR结 果在变化趋势和量级上均有较高的一致性, 但在13世 纪末至18世纪末SLR结果表现出的SIE增长趋势较 PCR 结果更为明显. PCR方法对 OR模型优化后, 解释 方差为 $0.40 / 0.36, R E$ 为 $0.28 / 0.23, F$ 值为 $11.50 / 9.70$, 可
以看出PCR方法较好的解决了 OR模型的过拟合问题. 对于存在多重共线性的代用资料集, 不宜直接采用普 通多元回归法 $(\mathrm{OR})$ 进行重建, 需先对代用资料集进行 权重合成或者主成分分析后, 再进行计算, 可有效避 免模型过拟合.

\subsection{3 偏最小二乘回归法(PLSR)重建结果}

为了进一步评估上述重建方法的稳定性和可靠 性, 采用偏最小二乘回归法(PLSR)重建目标海区SIE与 前述结果作对比. 不同于前述方法，用PLSR建模时采 用了表1中的全部代用资料. 采用不同主成分个数分别 建立PLSR回归模型并计算 $F$ 值、MSE、解释方差和 $\mathrm{RE}$, 综合比较这些参数确定最佳的主成分数. 从图 $5 \mathrm{a} 1$ 可看出, 随着主成分数的增加, 解释方差增大, MSE减 小. 当主成分个数超过 6 时, 解释方差和MSE几乎没有 变化. 从图 $5 \mathrm{c} 1$ 可看出, RE值在主成分超过 3 个时开始 大幅度下降, 从第 5 个值开始出现负值, 模型出现过拟

表 2 代用资料间的相关系数a)

\begin{tabular}{ccccccc}
\hline 代用资料标号 & Proxy 1 & Proxy 4 & Proxy 5 & Proxy 6 & Proxy 7 & Proxy 9 \\
\hline Proxy 1 & 1.00 & 0.32 & $0.58^{*}$ & 0.28 & $0.36^{*}$ & 0.23 \\
Proxy 4 & & 1.00 & $0.47^{*}$ & 0.01 & -0.06 & $0.40^{*}$ \\
Proxy 5 & & 1.00 & 0.20 & 0.13 & $0.61^{*}$ \\
Proxy 6 & & & 1.00 & 0.30 & 0.29 \\
Proxy 7 & & & & 1.00 & 0.19 \\
Proxy 9 & & & & & & 1.00 \\
\hline
\end{tabular}

a) *表示通过 0.05 显著性检验

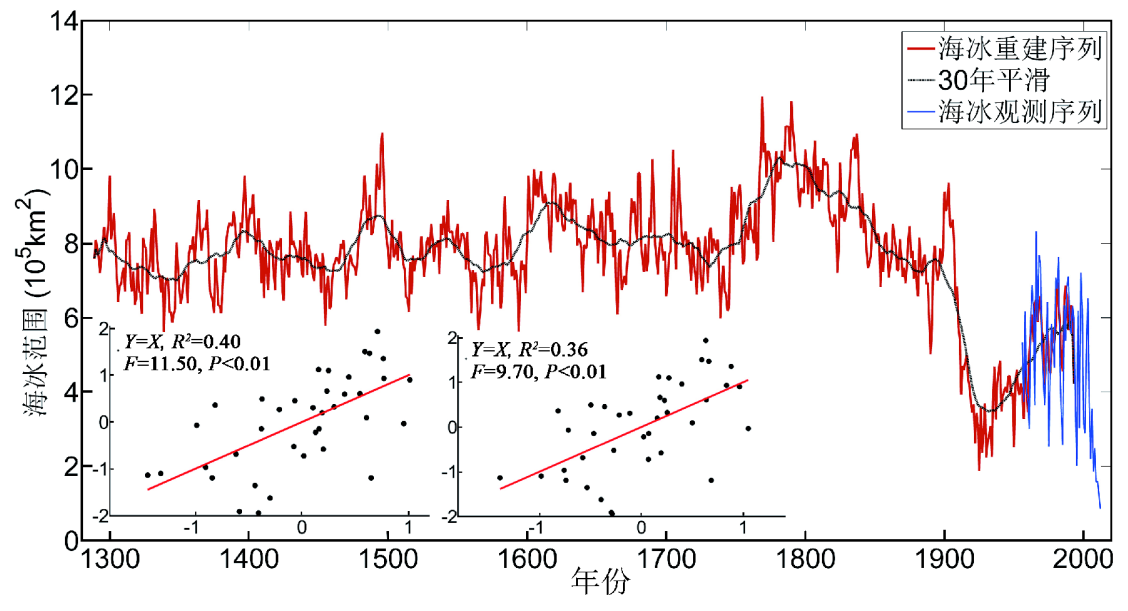

图 4 主成分回归法(PCR)重建结果 

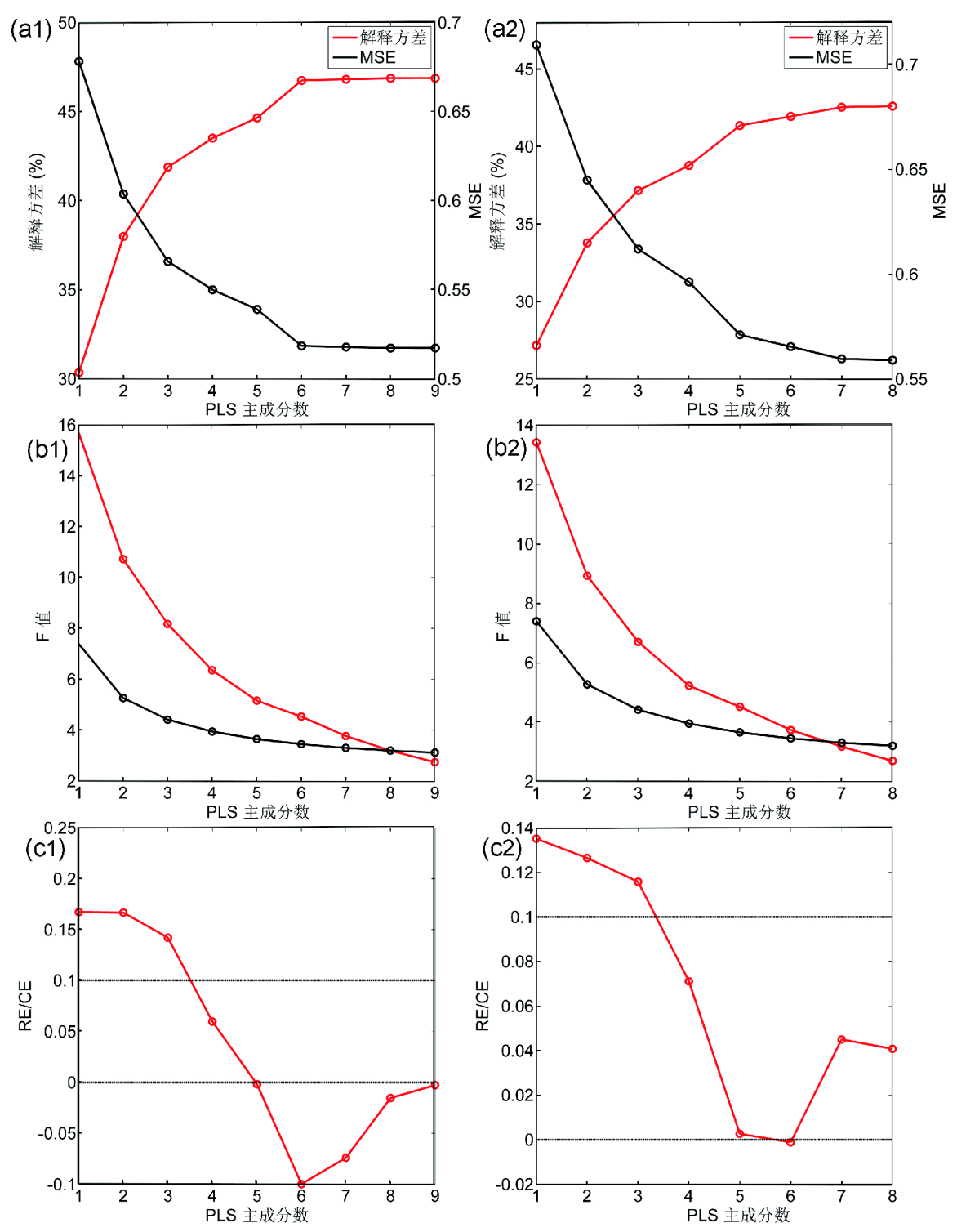

图 5 偏最小二乘回归法不同主成分的统计参数比较

(a1) (c1)表示第一段重建(1402 1993); (a2) (c2)表示第二段重建(1289 1401)

合, 结果稳定性较差. 综合考虑选用前 3 个主成分来构 建回归模型. 同理, 在第二段重建中(图5a2 c2)也选用 前3个主成分来进行计算.

最终得出的重建结果(图6)与SLR和PCR的结果尽 管在年际-年代际尺度上也存在一些不一致, 但在多年 代际-百年尺度上它们之间有非常高的一致性, 大的冷 暖时期和变化趋势都非常对应. 均表现出: B-K海秋季 SIE在13世纪末到18世纪末这段时间处于高位波动变 化, 且有小幅上升趋势. 在 18 世纪末期至20世纪30 40
年代SIE迅速减小, 其中19世纪末期SIE开始加速退缩, 20世纪30 40年代是 SIE的相对低值期. 20 世纪 40 70 年代SIE有所扩大, 70 年代后又开始持续减小. 但需指 出的是, 类似于PCR, PLSR重建结果表现出的13世纪 末到18世纪末SIE增加趋势不如SLR明显, 同时PLSR 结果表现出的年际间振荡信号更强.

\section{2 不同方法重建结果的对比与评估}

本文采用几种不同的统计方法重建了B-K海过去 


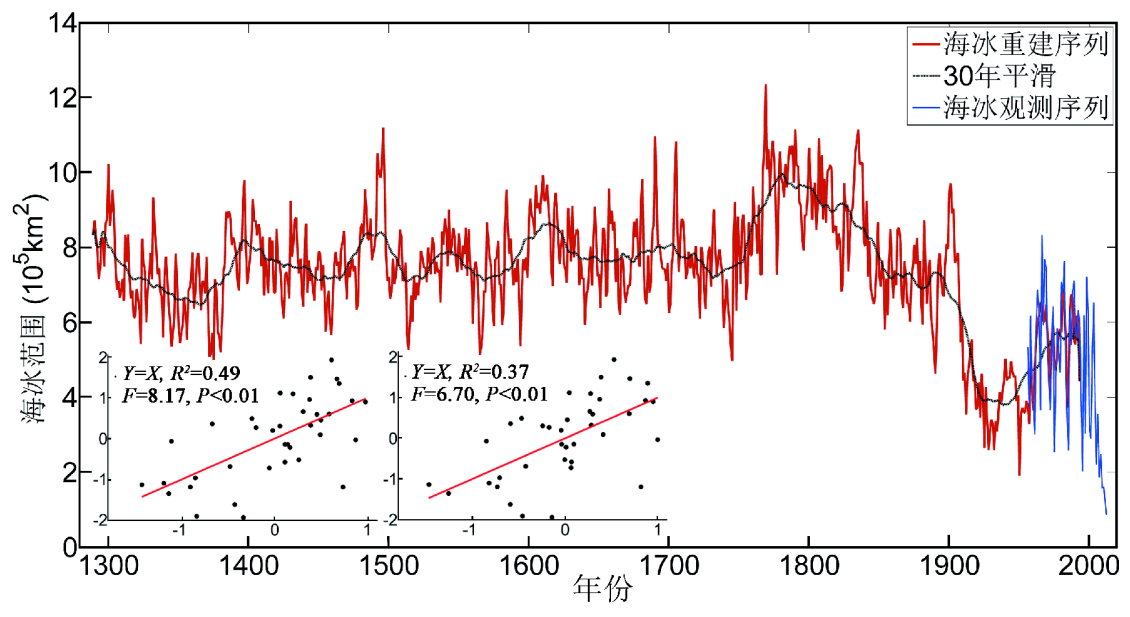

图 6 偏最小二乘回归法(PLSR)重建结果
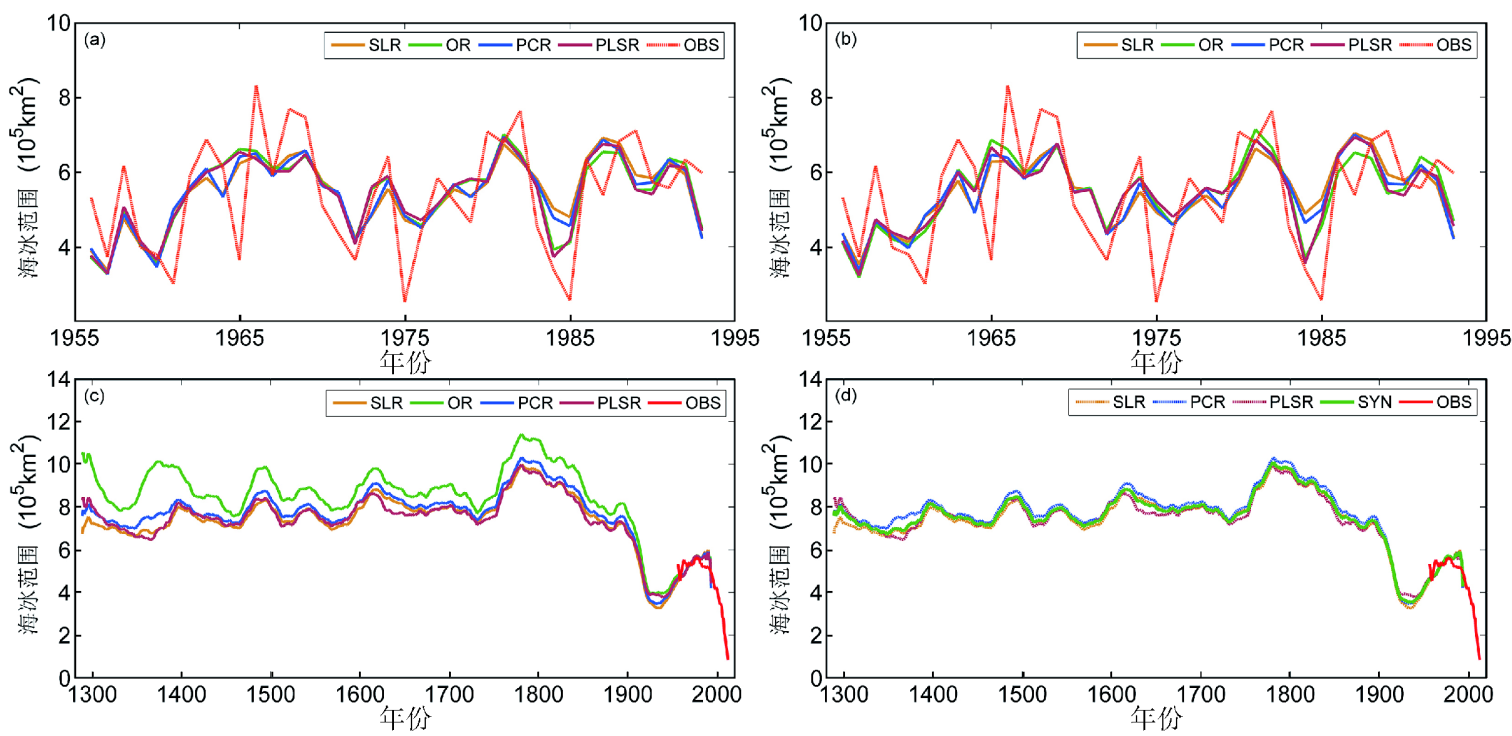

图 7 不同重建方法的结果及其与观测序列之间的比较

(a)和(b)分别表示两段重建(1402 1993和1289 1401)在校准时段的序列对比，其实OBS为海冰观测序列; (c)和(d)表示整个重建时段的结果对 比(30年平滑), (d)中SYN为海冰合成结果

700多年的秋季SIE，并对结果进行了初步的比较和分 析. 除了OR结果过拟合使得结果偏差较大，其余三种 方法的结果一致性较高. 下面进一步根据各模型的统 计参数对各重建结果进行讨论, 详见表3. 这几种方法 均可在一定程度上重建出北极海冰的变化趋势，在标 定时段各结果和海冰观测资料的峰谷对应较好(图 $7 \mathrm{a}$ 和 $7 b)$, 重建值与观测值的相关性很高 $(p<0.01), \mathrm{D}-\mathrm{W}$ 检 验参数均在 2 左右, 表明模型的残差独立, 且RE值均为 正, $F$ 值较高 $(p<0.01)$, 表明重建结果具有一定的可靠
性, 具有重建意义. 尽管 OR模型的结果在标定时段表 现最好(解释方差: 0.43/0.40), 但是模型过度拟合, 泛化 能力较差(代用资料减小, $\mathrm{RE}$ 和 $F$ 值却变大). 虽偏差较 小(标定时段), 方差却较大, 模型对代用资料的微小变 化十分敏感，最终重建结果的偏差也会被放大(图7c). 剩下三种方法, PLSR的解释方差最高, 且没有过拟合. SLR和PCR结果更相近, 总体差别不大, 但PCR模型的 解释性略优于SLR, 泛化能力稍逊于SLR. 在模型均未 过拟合的情况下，我们更看中模型的解释能力. 剔除 


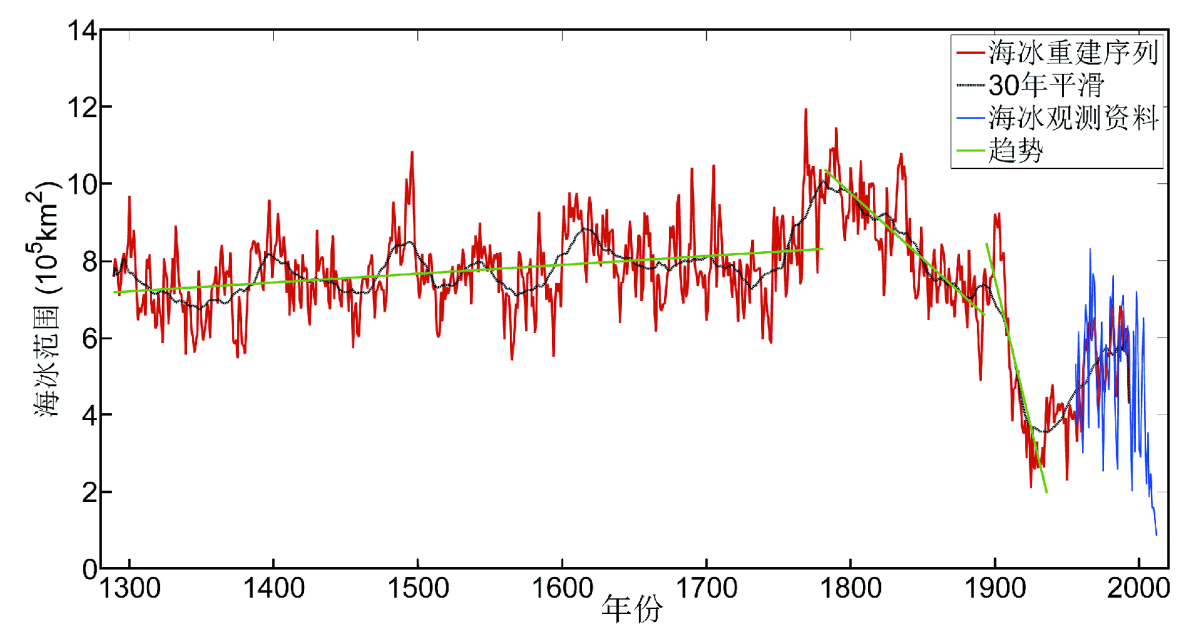

图 8 1289 1993年B-K海秋季SIE重建合成结果

表 3 不同重建方法的统计参数对比 ${ }^{\mathrm{a})}$

\begin{tabular}{ccccccc}
\hline 方法 & 代用资料数量 & 相关系数 & 解释方差 & RE & D-W统计 & $F$ \\
\hline SLR-1 & 6 & 0.62 & 0.36 & 0.31 & 1.99 & 21.99 \\
SLR-2 & 5 & 0.57 & 0.32 & 0.26 & 1.97 & 17.62 \\
OR-1 & 6 & 0.66 & 0.43 & 0.17 & 2.10 & 3.95 \\
OR-2 & 5 & 0.64 & 0.40 & 0.19 & 2.20 & 4.34 \\
PCR-1 & 6 & 0.63 & 0.40 & 0.28 & 2.04 & 11.50 \\
PCR-2 & 5 & 0.60 & 0.36 & 0.23 & 2.03 & 9.70 \\
PLSR-1 & 9 & 0.65 & 0.42 & 0.14 & 2.14 & 8.17 \\
PLSR-2 & 8 & 0.61 & 0.37 & 0.12 & 2.15 & 6.70 \\
\hline
\end{tabular}

a) 相关系数和 $F$ 值均可通过 0.01 显著性检验; 标号 $1 、 2$ 分别表示两个重建时段

OR模型, 将SLR, PCR 和PLSR的结果用解释方差做权 重合成, 得到最终的重建结果(图7d和图8). 最终合成 序列的解释方差为 0.41 , 与 SIE观测值的相关系数为 $0.64(p<0.01)$.

B-K海秋季SIE的变化与北极地区气温变化高度相 关. 13 世纪末到18世纪末, B-K海SIE处于高位振荡期, 与小冰期(LIA)对应, 且有小幅上升趋势 $\left(230 \mathrm{~km}^{2} \mathrm{a}^{-1}\right)$. Kaufman等(2009)提出北极地区900 1760年气温偏低 且有一定的降温趋势, 这也与B-K海SIE在这个阶段的 扩张趋势对应. 在该时段内, 14世纪、15世纪、15世纪 90 年代、16世纪30 40年代、17世纪20 30年代、 18 世纪80 90年代是SIE较高的时期; 14 世纪40 60年 代、15世纪60 70年代、16世纪 20 年代、16世纪 $60 \sim 80$ 年代和 18 世纪30 40年代是SIE较低的时期. 从
18世纪末开始，B-K海SIE开始持续减小，18世纪末至 19 世纪末SIE减小速率为 $3.4 \times 10^{3} \mathrm{~km}^{2} \mathrm{a}^{-1}, 19$ 世纪后期 开始加速减小 $\left(1.5 \times 10^{4} \mathrm{~km}^{2} \mathrm{a}^{-1}\right)$, 减小速率为之前平均 的3.68倍. 20 世纪30 40年代是B-K海SIE的一个相对低 值期, 20世纪40 70年代SIE有所回升, 20世纪70年代后 又持续减小并一直持续至今, 且这个阶段SIE减小速率 是 13 世纪末至 18 世纪末退缩阶段平均速率的 6.18 倍. 前人研究表明, 20 世纪 40 年代是北极地区的相对温暖 期, 之后北极进入一个降温阶段直到70年代后又开始 持续增暖(Suo等, 2013; Soon等, 2015), 这与本文重建 结果对应.

将本文的重建结果进一步与北极地区及北半球的 其他相关气候重建资料进行对比验证(图9). 这些资料 分别为: 用深海沉积物IP25重建的巴伦支海春季海冰 


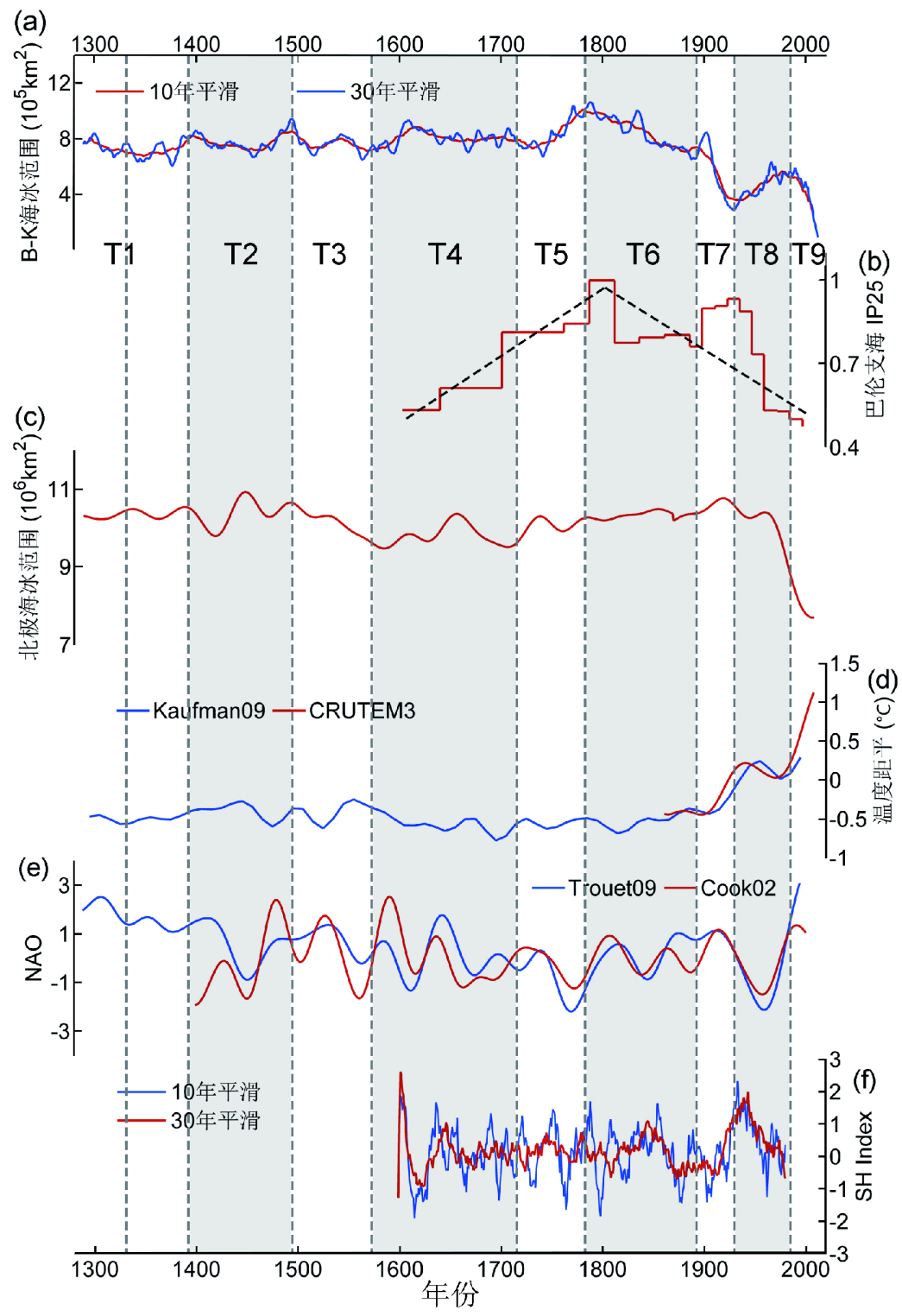

图 9 重建结果与其他相关重建结果的对比

(a) 本次重建结果; (b) 基于IP25重建的巴伦支海冰情(Vare等, 2010); (c) 8月北极SIE(Kinnard等, 2011); (d) 北极温度重建结果(Kaufman等, 2009) 以及CRUTEM3 北极温度资料; (e) NAO重建结果(Cook等, 2002; Trouet等, 2009); (f) 冬季西伯利亚高压指数(SH Index)重建结果(D’Arrigo等, 2005)

冰情(图9b)、夏末北极SIE重建序列(图9c)、北极温度 重建序列(图9d)、NAO重建序列(图9e)及西伯利亚高 压指数重建序列(图9f). 本文重建结果表明B-K海SIE (图9a)从 $\mathrm{T} 6$ 开始持续减小, 与图9b变化趋势一致, 也与 北极温度变化(图9d)对应. 具体表现为: 从 $\mathrm{T} 7$ 阶段开始, B-K海SIE(图9a)开始加速减小, 与北极温度(图9d)加速 上升的趋势对应; T8阶段是B-K海SIE(图9a)减小过程 中的一个回升期，与此对应，图9d表明该阶段为降温 期. B-K海 SIE(图9a)与北极 SIE(图9c)的变化趋势在T8 和T9阶段均表现为大幅减小, 但两者在T6和T7阶段有 差异, 这也说明了SIE具有区域性的变化特征. T6之前, B-K海SIE处于高位波动的状态，且有小幅上升趋势， 与北极温度处于低位震荡并有小幅降温趋势相对应 (图9d). 图9b也表现出巴伦支海SIE在T4和T5阶段处于 
一个上升期, 趋势与本文结果一致, 但其量级过大(T4 阶段的SIE与T8阶段相近). 本文重建结果与其他结果 除了在变化趋势上有一致性, 在峰谷值上也存在一定 的对应. 例如, T4是B-K海SIE的高值期, 该时期整个 北极SIE也较大(图9c), 表明整个北极处于一个较冷的 阶段(图9d). T2为B-K海SIE的相对低值期, 这个阶段 北极地区温度偏高(图9d). T1和T3阶段的对应性一般, 但也有一些对应的峰谷, 如 T1中虚线表示的时期. 进 一步对比B-K海SIE序列和NAO重建序列(图9e)可以发 现, SIE偏高(低)的时期往往对应NAO负(正)位相时期, 这与许多研究结果一致(Serreze等, 2007; Petoukhov和 Semenov, 2010; Cohen等, 2014), 但在一些时段这种关 系并不一一对应的, 存在着一定的超前滞后期. 一些学 者曾提出的B-K海区秋季海冰异常偏少会通过影响大 气环流型使得该年冬季西伯利亚高压偏高(Honda等, 2009; Petoukhov和Semenov, 2010; Wu等, 2011; Hopsch 等, 2012; Tang等, 2013). 对比图9a和图9f可以看出, 在 不同的气候时期B-K海秋季SIE与冬季西伯利亚高压 强度的对应关系并不稳定. T7 和T8阶段, B-K秋季SIE 与冬季西伯利亚高压指数对应关系为负相关, 但在气 候冷期背景下(T6之前)对应关系并不稳定, 如 $\mathrm{T} 4$ 前期 和 $\mathrm{T} 5$ 后期两者为负相关, 但 $\mathrm{T} 4$ 后期, $\mathrm{T} 5$ 前期及 $\mathrm{T} 6$ 阶段 两者无明显的对应关系.

\section{4 结论}

本文通过对北极地区巴伦支海-喀拉海周边岛屿 和大陆上的气候代用资料进行笁选, 选用指代意义强 的冰芯和树轮资料, 用不同方法进行重建并对结果进 行对比和融合, 最终重建了1289 1993年B-K海秋季 SIE序列. 重建结果表明, 13世纪末至18世纪末B-K海 SIE处于高位震荡状态, 且有小幅上升趋势, 并有6次明 显的高低位交替期, 这与小冰期内气候冷暖交替相对 应. 虽然SIE序列表现的具体冷暖期与北极温度序列 的对应关系存在一定的超前或滞后, 但两者整体的变 化趋势是较为一致的. 18 世纪末期以来B-K海SIE减小 的持续时间和速率都是在重建时段内前所未有的. 20 世纪70年代后SIE退缩尤为显著, 退缩速率是以往退 缩期(重建时段)均值的6.18倍. 因此, 20 世纪70年代以 来很可能是过去近千年北极海冰退缩最显著的时期, 这与IPCC AR5(IPCC, 2013)关于全球气温变化的历史
判断相似, 很可能与工业革命以来的人类活动有关. 北极海冰是气候系统中一个复杂的分量, 其变化 受到了温度, 大气环流, 洋流, 盐度等多因子的共同作 用, 演变机理极其复杂. 利用冰芯和树轮等陆源气候代 用资料来重建历史时期北极SIE的变化，目前在年际年代际尺度上还存在较多不确定性, 需要融合古气候 模式(Bothe等, 2015; Yang和Jiang, 2017)及高质量的代 用资料来进一步改进重建结果. 此外, 虽然我们重建了 对激发东亚极端天气气候事件非常敏感的 B-K海区 $\mathrm{SIE}$, 但毕竟北冰洋整体海冰变化以及各海区间相互作 用更加重要, 有待我们今后掌握更多代用材料并深入 研究, 得到全北冰洋和分海区的重建序列.

致谢感谢德国AWI(Alfred Wegener Institute)Dr. Opel Thomas提供北地群岛冰芯资料, 改进了本文的重建结果. 美国哥伦比亚大学Dr. Rosanne D'Arrigo提供冬季西伯利 亚高压指数(SHI)重建序列, 与本文重建结果做对比分析. 感谢中国科学院西北生态环境资源研究院杨佼和中国气 象科学研究院韩微对重建思路提供了指导和帮助.

\section{参考文献}

武炳义, 市林根, 张人禾. 2004. 冬季北极涛动和北极海冰变化对东 亚气候变化的影响. 极地研究, 16: 211-220

武炳义, 杨琨. 2016. 从2011/2012和2015/2016年冬季大气环流异常 看北极海冰以及前期夏季北极大气环流异常的作用. 气象学报, 74: 683-696

Abram N J, Wolff E W, Curran M A J. 2013. A review of sea ice proxy information from polar ice cores. Quat Sci Rev, 79: 168-183

Barnes E A. 2013. Revisiting the evidence linking Arctic amplification to extreme weather in midlatitudes. Geophys Res Lett, 40: 47344739

Barnes E A, Screen J A. 2015. The impact of Arctic warming on the midlatitude jet-stream: Can it? Has it? Will it? WIREs Clim Change, 6: $277-286$

Benassai S, Becagli S, Gragnani R, Magand O, Proposito M, Fattori I, Traversi R, Udisti R. 2005. Sea-spray deposition in Antarctic coastal and plateau areas from ITASE traverses. Ann Glaciol, 41: 32-40

Bothe O, Evans M, Donado L F, Bustamante E G, Gergis J, GonzalezRouco J F, Goosse H, Hegerl G, Hind A, Jungclaus J H, Kaufman D. 2015. Continental-scale temperature variability in PMIP3 simulations and PAGES $2 \mathrm{k}$ regional temperature reconstructions over the past millennium. Clim Past, 11: 1673-1699

Cohen J, Screen J A, Furtado J C, Barlow M, Whittleston D, Coumou 
D, Francis J, Dethloff K, Entekhabi D, Overland J, Jones J. 2014. Recent Arctic amplification and extreme mid-latitude weather. Nat Geosci, 7: 627-637

Cook E R, D’Arrigo R D, Mann M E. 2002. A well-verified, multiproxy reconstruction of the winter North Atlantic oscillation index since AD1400. J Clim, 15: 1754-1764

Curran M A J, van Ommen T D, Morgan V I, Phillips K L, Palmer A S. 2003. Ice core evidence for Antarctic Sea ice decline since the 1950s. Science, 302: 1203-1206

D'Arrigo R, Jacoby G, Wilson R, Panagiotopoulos F. 2005. A reconstructed Siberian High index since AD1599 from Eurasian and North American tree rings. Geophys Res Lett, 32: L05705

Fauria M M, Grinsted A, Helama S, Moore J, Timonen M, Martma T, Isaksson E, Eronen M. 2010. Unprecedented low twentieth century winter sea ice extent in the Western Nordic Seas since AD1200. Clim Dyn, 34: 781-795

Francis J A, Chan W, Leathers D J, Miller J R, Veron D E. 2009. Winter Northern Hemisphere weather patterns remember summer Arctic sea-ice extent. Geophys Res Lett, 36: L07503

Goosse H, Renssen H, Timmermann A, Bradley R S, Mann M E. 2006. Using paleoclimate proxy-data to select optimal realisations in an ensemble of simulations of the climate of the past millennium. Clim Dyn, 27: 165-184

IPCC. 2013. Climate Change 2013: The Physical Science Basis. Contribution of Working Group I to the Fifth Assessment Report of the Intergovernmental Panel on Climate Change. In: Hartmann D L, Klein Tank A M G, Rusticucci M, Alexander L V, Brönnimann S, Charabi Y, Dentener F J, Dlugokencky E J, Easterling D R, Kaplan A, Soden B J, Thorne P W, Wild M, Zhai P M, eds. Observations: Atmosphere and surface. Cambridge: Cambridge University Press

Henderson K A. 2002. An ice core paleoclimate study of Windy Dome, Franz Josef Land (Russia): Development of a recent climate history for the Barents Sea. Doctoral Dissertation. Columbus: Ohio State University

Helama S, Fauria M M, Mielikainen K, Timonen M, Eronen M. 2010. Sub-Milankovitch solar forcing of past climates: Mid and late Holocene perspectives. Geol Soc Am Bull, 122: 1981-1988

Honda M, Inoue J, Yamane S. 2009. Influence of low Arctic sea-ice minima on anomalously cold Eurasian winters. Geophys Res Lett, 36: L08707

Hopsch S, Cohen J, Dethloff K. 2012. Analysis of a link between fall Arctic sea ice concentration and atmospheric patterns in the following winter. Tellus Ser A-Dyn Meteorol Oceanol, 64: 18624

Inoue J, Hori M E, Takaya K. 2012. The role of Barents Sea Ice in the wintertime cyclone track and emergence of a warm-Arctic coldSiberian anomaly. J Clim, 25: 2561-2568
Isaksson E, Divine D, Kohler J, Martma T, Pohjola V, Motoyama H, Watanabe O. 2005a. Climate oscillations as recorded in svalbard ice core $\delta^{18} \mathrm{O}$ records between ad 1200 and 1997. Geogr Ann Ser APhys Geogr, 87: 203-214

Isaksson E, Kekonen T, Moore J, Mulvaney R. 2005b. The Methanesulfonic acid (MSA) record in a Svalbard ice core. Ann Glaciol, 42: 345-351

Isaksson E, Kohler J, Pohjola V, Moore J, Igarashi M, Karlöf L, Martma T, Meijer H, Motoyama H, Vaikmäe R, van de Wal R S W. 2005c. Two ice-core $\delta^{18} \mathrm{O}$ records from Svalbard illustrating climate and sea-ice variability over the last 400 years. Holocene, 15: 501509

Jones P. 2016. The reliability of global and hemispheric surface temperature records. Adv Atmos Sci, 33: 269-282

Jones P D, Mann M E. 2004. Climate over past millennia. Rev Geophys, 42: RG2002

Kaufman D S, Schneider D P, McKay N P, Ammann C M, Bradley R S, Briffa K R, Miller G H, Otto-Bliesner B L, Overpeck J T, Vinther B M, Abbott M, Axford Y, Bird B, Birks H J B, Bjune A E, Briner J, Cook T, Chipman M, Francus P, Gajewski K, Geirsdottir A, Hu F S, Kutchko B, Lamoureux S, Loso M, MacDonald G, Peros M, Porinchu D, Schiff C, Seppa H, Thomas E. 2009. Recent warming reverses long-term Arctic cooling. Science, 325: 1236-1239

Kekonen T, Moore J, Perämäki P, Mulvaney R, Isaksson E, Pohjola V, van W R S. 2005. The 800 year long ion record from the Lomonosovfonna (Svalbard) ice core. J Geophys Res, 110: D07304

Kinnard C, Zdanowicz C M, Fisher D A, Isaksson E, de Vernal A, Thompson L G. 2011. Reconstructed changes in Arctic sea ice over the past 1450 years. Nature, 479: 509-512

Lewis E R, Schwartz S E. 2004. Sea Salt Aerosol Production: Mechanisms, Methods, Measurements, and Models-A Critical Review. Washington D C: American Geophysical Union.152

Liu J, Curry J A, Wang H, Song M, Horton R M. 2012. Impact of declining Arctic sea ice on winter snowfall. Proc Natl Acad Sci USA, 109: 4074-4079

Liu J, Chen Z, Francis J, Song M, Mote T, Hu Y. 2016. Has Arctic sea ice loss contributed to increased surface melting of the Greenland ice sheet? J Clim, 29: 3373-3386

McCusker K E, Fyfe J C, Sigmond M. 2016. Twenty-five winters of unexpected Eurasian cooling unlikely due to Arctic sea-ice loss. Nat Geosci, 9: 838-842

Motoyama H, Watanabe O, Goto-Azuma K, Igarashi M, Miyahara M, Nagasaki T, Karloef L, Isaksson E. 2001. Activities of the Japanese Arctic Glaciological Expedetion in 1999 (JAGE 1999). Technical Report. Memoirs of National Institute of Polar Research. Special issue, 54: $253-260$ 
Muscheler R, Joos F, Beer J, Müller S A, Vonmoos M, Snowball I. 2007. Solar activity during the last $1000 \mathrm{yr}$ inferred from radionuclide records. Quat Sci Rev, 26: 82-97

Opel T, Fritzsche D, Meyer H. 2013. Eurasian Arctic climate over the past millennium as recorded in the Akademii Nauk ice core (Severnaya Zemlya). Clim Past, 9: 2379-2389

Overland J, Francis J A, Hall R, Hanna E, Kim S J, Vihma T. 2015. The melting Arctic and midlatitude weather patterns: Are they connected? J Clim, 28: 7917-7932

PAGES 2k Consortium. 2013. Continental-scale temperature variability during the past two millennia. Nat Geosci, 6: 339-346

Petoukhov V, Semenov V A. 2010. A link between reduced BarentsKara sea ice and cold winter extremes over northern continents. J Geophys Res, 115: D21111

Röthlisberger R, Mulvaney R, Wolff E W, Hutterli M A, Bigler M, De A M, Hansson M E, Steffensen J P, Udisti R. 2003. Limited dechlorination of sea-salt aerosols during the last glacial period: Evidence from the European Project for Ice Coring in Antarctica (EPICA) Dome C ice core. J Geophys Res, 108: 4526

Röthlisberger R, Crosta X, Abram N J, Armand L, Wolff E W. 2010. Potential and limitations of marine and ice core sea ice proxies: An example from the Indian Ocean sector. Quat Sci Rev, 29: 296-302

Screen J A, Simmonds I. 2010. The central role of diminishing sea ice in recent Arctic temperature amplification. Nature, 464: 1334-1337

Screen J A, Simmonds I. 2012. Declining summer snowfall in the Arctic: Causes, impacts and feedbacks. Clim Dyn, 38: 2243-2256

Serreze M C, Holland M M, Stroeve J. 2007. Perspectives on the Arctic's shrinking sea-ice cover. Science, 315: 1533-1536

Shapiro I, Colony R, Vinje T. 2003. April sea ice extent in the Barents
Sea, 1850-2001. Polar Res, 22: 5-10

Soon W, Connolly R, Connolly M. 2015. Re-evaluating the role of solar variability on Northern Hemisphere temperature trends since the 19th century. Earth-Sci Rev, 150: 409-452

Suo L, Otterå O H, Bentsen M, Gao Y, Johannessen O M. 2013. External forcing of the early 20th century Arctic warming. Tellus Ser A-Dyn Meteorol Oceanol, 65: 20578

Tang Q, Zhang X, Yang X, Francis J A. 2013. Cold winter extremes in northern continents linked to Arctic sea ice loss. Environ Res Lett, 8: 014036

Trouet V, Esper J, Graham N E, Baker A, Scourse J D, Frank D C. 2009. Persistent positive North Atlantic oscillation mode dominated the medieval climate anomaly. Science, 324: 78-80

Vare L L, Massé G, Belt S T. 2010. A biomarker-based reconstruction of sea ice conditions for the Barents Sea in recent centuries. Holocene, 20: 637-643

Walsh J E. 2014. Intensified warming of the Arctic: Causes and impacts on middle latitudes. Glob Planet Change, 117: 52-63

Wu B Y, Su J Z, Zhang R H. 2011. Effects of autumn-winter Arctic sea ice on winter Siberian High. Chin Sci Bull, 56: 3220-3228

Xiao C, Dou T, Sneed S B, Li R, Allison I. 2015. An ice-core record of Antarctic sea-ice extent in the southern Indian Ocean for the past 300 years. Ann Glaciol, 56: 451-455

Yang K, Jiang D. 2017. Interannual climate variability change during the medieval climate anomaly and Little Ice Age in PMIP3 last millennium simulations. Adv Atmos Sci, 34: 497-508

Yang X, Pyle J A, Cox R A. 2008. Sea salt aerosol production and bromine release: Role of snow on sea ice. Geophys Res Lett, 35: L16815

(责任编委: 黄建平) 